\title{
Human Papillomavirus-Related Malignant Neoplasm in AIDS Patient
}

National Cancer Institute

\section{Source}

National Cancer Institute. Human Papillomavirus-Related Malignant Neoplasm in AIDS

Patient. NCI Thesaurus. Code C102884.

A malignant neoplasm caused by human papillomavirus in an a patient with a history of AIDS. 